\title{
7 Weshalb wird Gewalt ausgeübt? Oder die Frage nach den Rechtfertigungsmustern und Legitimationsstrategien
}

Die Täter neigen zu Selbstrechtfertigungsideologien, Rechtfertigungskonstrukten und „Scheinplausibilitäten“ (Tietze 2003). Nach Meinung von Tietze geht bei den Tätern aufgrund ihrer Realitätsverkennung die Sensibilität für den „Zusammenhang von Zweck und Mittel“ verloren. Dadurch wollen sie ihre subjektiv empfundenen Not-, Krisen- und Problemlagen mit dem imaginierten Feind verknüpfen und eine explosive Situation des „Ich gegen sie“ herstellen. Durch Gewalt kann sich der Amokläufer aus einer „Position der Ohnmacht in eine des aktiven Handelns“ (Günter 2011) versetzen. Durch Rache und Unterwerfung anderer kann er sich seines „Selbstwertgefühls und seiner Überlegenheit“ versichern. Dies führt auch zu einer „Entmenschlichung“ der anderen und zum Abbruch der Kommunikation in Verbindung mit der Idee, die zu vernichten, die ihm im Weg stehen.

Gewaltlogiken von „Reinheit“, Erlösungsideen, mit der Absicht, anderen ihr Lebensrecht abzusprechen, enthalten immer auch eine „wahnhafte Rationalität“, die Gewalt und Vernichtung oberflächlich plausibel macht. Der Wahn, in welcher Maske auch immer, liefert nach Schneider (2010) den „Universaltreibstoff“ des Attentats. Seiner Meinung nach entspringt der Wahn einer „paranoischen Fatumsgewissheit“, die weder Zweifel noch Zufall kennt. Was jeder Außen- 
7 Weshalb wird Gewalt ausgeübt?

Oder die Frage nach den Rechtfertigungsmustern und Legitimationsstrategien

stehende als „Durchbrennen der Vernunftsicherung“ klassifiziert, gehorcht stattdessen einer „,besonderen Betriebsart der Vernunft“, nämlich der „paranoischen Variante“, was noch durch die „Proliferation des Schreckens“ der Medien verstärkt wird. Die neuen Helden erleben sich „gottähnlich“.

„ICh bin Gott! KILL MANKIND!“ kritzelte Eric Harris, ehe er seinen Amoklauf durch die Columbine Highschool 1999 antrat. 